Athens Journal of Mass Media and Communications

Volume 8, Issue 3, July 2022 - Pages 145-160

\title{
No News is Not Good News: The Implications of News Fatigue and News Avoidance in a Pandemic World
}

\author{
By Neill Fitzpatrick*
}

In an era dominated by a constant flow of grim news, news fatigue is becoming more recognized as a serious concern, even a health risk. Around-the-clock reports on the pandemic can seem unavoidable, along with ongoing coverage of political upheaval, climate change, and other major global issues. For some, the weight of the world's news becomes too much. A 2019 pre-pandemic survey of 12,000 American adults by the Pew Research Center found 66\% admitting they were "worn out" by the sheer amount of news available to them. News fatigue can translate into a desire to consume less news in an effort to preserve and protect one's mental health. A Pew Research Center survey in April 2020 determined $71 \%$ of adult Americans say they need to "take breaks from COVID19 news" while $43 \%$ said the news "leaves them feeling worse emotionally". The World Health Organization addressed the concerns about the impact of the news onslaught in the "Mental Health Tips" section of its website. The WHO offers this advice to the public: "Try to reduce how much you watch, read or listen to news that makes you feel anxious or distressed". Growing numbers are heeding this advice and reducing their news consumption. Some are opting for no news whatsoever as a means of coping. In May 2020, the Reuters Institute for the Study of Journalism at Oxford University examined the "infodemically vulnerable" in Britain, those who chose to reduce consumption of COVID-19 related news. More than one-fifth of those surveyed said: "they often or always actively try to avoid the news," with the majority citing the impact on their mood. While mental health concerns appear to be the primary reason behind the increase in avoidance, growing distrust in mainstream media is also cited. While not a new phenomenon, the skepticism surrounding journalism was exacerbated during the pandemic as anti-vaccination advocates and conspiracy theorists questioned the validity and accuracy of the COVID-19 facts shared by news organizations, even governments. In this analysis of research, interviews, news articles, and social media content, I will advance recommendations for journalism researchers seeking to understand these issues. I will also propose strategies for journalists and news organizations seeking to navigate the issues and find solutions to help their embattled profession survive and recover.

Keywords: journalism, news avoidance, news fatigue, misinformation, trust

\section{Introduction}

For most of 2020 and 2021, the world has been in the grips of the COVID-19 pandemic. The health crisis has generated a barrage of news and information about the virus, its victims, and its overall impact. The Economist called it the most

\footnotetext{
*Assistant Professor, MacEwan University, Canada.
} 
dominant news story since the Second World War (The Economist, 2020). It is not difficult to feel overwhelmed by the amount of news related to the pandemic alongside the many other significant global stories, including political upheaval, race-related protests, and climate change. Still, it is the news of the coronavirus that has dominated news coverage for more than a year. In May 2021, a Google search for the term "COVID-19 news" yielded more than 25.2 billion results. The majority of these stories share common factors such as negative headlines (Aslam, 2020) and grim statistics about COVID-19's death toll, as well as its impact on families, businesses, and health care workers (Sacerdote et al., 2020). For the millions locked down in their homes and working from home offices, the news is the constant connection to the outside world. Whether from social media or more traditional sources, the headlines are all but unavoidable and an incessant reminder of the health crisis. As the coronavirus spread around the world, it was not long before the amount of pandemic information available on various media became staggering and, for some, overwhelming. By April 2020, the World Health Organization was using the term "infodemic" to describe the torrent of COVID-19 news and information emanating from traditional sources, social media, even friends and family members. The WHO also introduced the term "infodemiology", defining it as "the study of that information and how to manage it" while providing a list of tips to help consumers "identify misinformation or disinformation" (World Health Organization, 2020b). It is important to point out that this deluge of news was a growing concern prior to the pandemic. During the presidency of Donald Trump from 2016 to 2020, the daily news cycle - those stories deemed most important and significant by journalists - was described as "insane" and "actionpacked" (Kight, 2017). The mainstream media's coverage of President Trump's announcements and antics, as well as other significant issues, created a seemingly endless news cycle readily available to news consumers anytime on-demand, thanks to 24-hour television news channels and social media platforms. News fatigue seemed an inevitable side effect of this information saturation. In both 2018 and 2019, the Pew Research Center surveyed 12,000 American adults on the topic of news-induced fatigue. Each study found about two-thirds of the respondents admitting they were "worn out" by the sheer amount of news available to them (Gottfried, 2020). By April 2020, as the pandemic intensified, so did the fatigue factor. A 2020 Pew Research Center survey of 10,000 American adults found $71 \%$ saying they felt the need to "take breaks from COVID-19 news", while $43 \%$ said the news "leaves them feeling worse emotionally" (Mitchell et al., 2020). This research will examine one of the repercussions of news fatigue: news avoidance, when consumers temporarily or completely stop reading, watching, or listening to the news. For some, it may be an exercise in moderation as they limit how much news they consume. For others, it is a conscious decision to shun all forms of news altogether. This trend raises questions about the impact of such shunning on news consumers and on the journalism industry and what, if anything, can be done to slow or reverse it? 


\section{Research Problem}

This is a descriptive study of the effects of constant news coverage and news consumption of information stemming from significant events or issues over an extended period. Specifically, the constant flow of pandemic-related news is triggering news fatigue among some consumers and prompting them to limit or avoid news consumption, temporarily or completely.

\section{Research Questions}

Through the analysis of existing data and new perspectives gleaned from interviews, I will endeavor to provide answers to the following questions:

What is the impact of news avoidance on consumers and on journalism as an industry?

Is news avoidance a short-term, pandemic-related phenomenon, or is it a trend attributed to issues such as distrust of news media or a decline in the overall quality of journalism?

What can news organizations do to convince the public of the importance of staying informed by professional journalists during a life-threatening global event?

How can journalists and news organizations best demonstrate they are relevant, reliable, and necessary sources of information, thereby regaining the trust of the public?

\section{Methodology}

This qualitative research is an analysis of news stories, opinion articles, and social media content primarily between January 2020 and June 2021. The news stories and opinion articles focused on the issues of the increased volume of news in recent years as well as on news consumption and the growing evidence of anxiety, stress, and "fatigue" caused by the constant barrage of news available to consumers. The stories and opinion articles were found on the websites of mainstream media outlets in North America and Europe as well as in studies and surveys conducted by journalism-related organizations. For example, the Pew Research Center, an American organization that studies journalism and other topics, found in an April 2020 survey that "the continuous news churn has had an impact. A majority of Americans say they need to take breaks from it, many say it makes them feel worse emotionally and half say they find it difficult to sift through what is true and what is not" (Mitchell et al., 2020). This material was supplemented with theories and research from academic research papers and journals discussing news consumption and related topics such as human behavior, trust in journalism, and the relevance of inclusion and diversity in the news industry. One example is the study Sentiments and emotions evoked by news 
headlines of coronavirus disease (COVID-19) outbreak which examined more than 141,000 news headlines pertaining to COVID-19 and the pandemic and found "Fear, trust, anticipation, sadness, and anger were the main emotions evoked by the news headlines" (Aslam, 2020). To determine the growing prevalence and increased public awareness of terms such as "news fatigue" and "COVID-19 news", Google searches with these words were conducted. The research also utilized unobtrusive observation, based on 30 years of experience as a journalist, to examine the growth of news fatigue and news avoidance before and during the global pandemic. In addition, interviews on these topics were conducted with journalists across Canada chosen for their experience, and for their insight into the news industry and the challenges facing the profession. The questions were as follows:

How do you respond to someone who says they have no need for news/journalism?

Some say traditional, professional journalism has become irrelevant. How do you respond to this?

In your opinion, what can journalists and news organizations do, or change, to restore confidence and trust in journalism and win back news avoiders?

The questions were sent to 31 journalists in January and February 2021. Responses were received from 14 journalists. While some of the interviewees have decades of experience, others are early in their journalism careers and have a different perspective on the challenges and potential solutions. This is relevant because the news industry has changed dramatically in the past two decades, especially, with the advent of the Internet and social media. The responses indicated that the younger journalists, those new to the profession, have different perspectives and opinions on the future of news than their more senior colleagues. As an example, one of the younger journalists responded with apparent frustration when asked what journalists and news organizations can do to restore trust and win back the news avoiders (question 3): "Stop with the bullshit. Stop with the trying to 'keep TV going' -- get in on technology instead of responding to it. Diversify positions of power" (BB, 2021). Given the subject matter and the critical, honest analysis requested, all names have been removed. Table 1 displays the initials used to identify the interviewees. 
Table 1. Initials Used to Identify the Interviewees

\begin{tabular}{|l|c|c|c|}
\hline Identifier & Title & Experience & Gender \\
\hline RA & Web journalist & 10 years & Female \\
\hline GC & $\begin{array}{c}\text { Senior editor/news } \\
\text { host }\end{array}$ & 25 years & Male \\
\hline SG & News anchor/producer & 35 years & Male \\
\hline BR & Senior producer/host & 25 years & Male \\
\hline MA & Video journalist & 5 years & Female \\
\hline BJ & Former journalist & 30 years & Male \\
\hline GR & News anchor/producer & 20 years & Female \\
\hline LJ & News manager & 20 years & Male \\
\hline OS & News manager & 15 years & Male \\
\hline MJ & Supervising producer & 30 years & Female \\
\hline ST & Retired news manager & 40 years & Male \\
\hline BB & Journalist & 15 years & Female \\
\hline MR & Journalist & 20 years & Female \\
\hline RG & Chief news anchor & 25 years & Male \\
\hline
\end{tabular}

The grounded theory approach was utilized to analyze the content of the stories, articles, and interviews and to identify recurring themes and categories. Developed by Glaser and Strauss in 1967, the purpose of the grounded theory qualitative methodology approach is to "construct theory grounded in data" (Corbin and Strauss 2015). However, this study's qualitative research is descriptive in nature. It is not intended to advance any new theory. Instead, the goal is to provide analysis and fresh insight into the recently intensified challenges of news fatigue and news avoidance as they relate to the present and the future of journalism. According to Corbin and Strauss, there is value to this descriptive approach as the analysis can add to existing knowledge and it "enables persons to take action and alter, contain, and change situations" (Corbin and Strauss, 2015). In the case of this research, the goals are to identify potential solutions to increased news fatigue and avoidance, encourage news organizations and journalists to evaluate and contain the current situation, and develop new methods of restoring public trust in journalism by better engaging news consumers with more relevant content.

\section{Significance of the Study}

While there has been substantial research into news consumption and its implications, there has been limited study of news avoidance. One reason is that news-induced fatigue and subsequent avoidance have only emerged as significant issues in recent years, from 2016 to 2021. This growth coincided with major, ongoing global stories such as the polarizing Brexit debate in Europe and the tumultuous American presidency of Donald Trump. Trump's rampant use of Twitter flooded inboxes, newspapers, and television screens due to the mainstream media's unbridled enthusiasm to report almost everything he said or posted. The president's highly politicized and often outrageous comments, combined with the non-stop, around-the-clock media coverage, spawned a news cycle that both 
titillated and alienated news consumers. The headlines and constant news alerts also caused stress for some, with one psychologist describing the condition as "headline stress disorder" and comparing the news onslaught to "missile explosions in a siege without end" (Stosny, 2017). While Trump raised eyebrows and Brexit boiled over, the extensive media coverage raised concerns about public trust - in both politicians and the news media (Newman, 2018). It was enough for some news consumers to tune out. By 2019, the Reuters Institute for the Study of Journalism's annual Digital News Report found 32\% of those surveyed worldwide said they "actively avoid" the news, with avoidance highest in Croatia (56\%), Turkey (55\%), and Greece (54\%) (Newman, 2020). As Trump and Brexit waned, the pandemic infected and monopolized the news cycle. Following a surge of interest in the first few months of 2020, consumers turned away, citing mental health concerns due to the largely negative COVID-19 headlines leaving them "feeling worse emotionally" (Mitchell et al., 2020). As more people choose to avoid the news, occasionally or completely, it is worthwhile to analyze the extent and impact of this avoidance.

\section{Literature Review}

\section{Aware or Worn Out?}

Humans have a thirst for knowledge. Whether around the corner or around the world, we feel a need to know what's going on and how it may affect our life. Indeed, some believe it is our "duty to keep informed" as responsible citizens (McCombs and Poindexter, 1983). This is not a new phenomenon, but what is new is the sheer amount of news available and accessible to people. The abundance of information at our fingertips has increased exponentially in the past 20 years due to advances in technology and the arrival of the internet and social media. It has never been easier for us to access information. As the enormity of the global pandemic became clear in 2020, millions were seeking the latest details from social media and from traditional sources such as radio and television news. In the early weeks of the pandemic, audience ratings, the measure of how many people watch newscasts, soared to unprecedented and unexpected levels for most news organizations (Johnson, 2020). As one journalist interviewed for this study stated: "Certainly, raw numbers are lower than they were in 2011/12 but we've seen a stunning revival in ratings over the past year as people clamour for the latest COVID news" (GC, 2021). This "clamour" was welcomed by journalists. They had witnessed a slow but steady decline in viewers, listeners, and readers between 2010 and 2020 as growing numbers of consumers, especially the younger demographic, chose to gather news from social media platforms rather than traditional sources (Wakefield, 2016). The pandemic, and the desire to stay up to date on the latest developments, changed this. According to another veteran television journalist: "The best news and perhaps the most surprising: our ratings data shows more people are watching our newscasts than ever before" (SG, 2021). Again, it's important to emphasize this consumer thirst for details occurred early in 
the pandemic when the story was changing daily, even by the hour. The 24-hour television news channels also saw audience increases, especially during live broadcasts of announcements by politicians and health officials. "I actually think the pandemic has been the best thing ever for local news and we have seen an unprecedented resurgence of viewers. It has literally put our 24 hours channel on the map" (MJ, 2021). However, this audience surge soon became another victim of the pandemic, as consumers turned away, admitting they felt overwhelmed by the constant flow of information. In May 2020, the Reuters Institute for the Study of Journalism at Oxford University examined the "infodemically vulnerable" in Britain, people who chose to lessen the consumption of COVID-19 related news. More than one-fifth of those surveyed said "they often or always actively try to avoid the news" with the majority citing the impact on their moods (Kleis Nielsen et al., 2020). One year later, a similar sentiment was detected in Canada. In May 2021, more than two-thirds (69\%) of 1002 Canadians surveyed admitted being "burned out when it comes to consuming news about the pandemic" (Bricker, 2021) and more than half (53\%) agreed that news organizations should "focus less on COVID-19 and more on other important stories" (Bricker, 2021). At the same time, however, the perception of the news media's effectiveness is quite favorable, with 59\% of those surveyed agreeing the coverage helped contain the spread of COVID-19 in Canada. Research has confirmed the mental health impact of news consumption. One study found heightened anxiety, even sadness, in people who watched negative news-related material, such as bulletins, after only minutes (Johnston \& Davey, 1997). The material shown to the study participants in 2011 was edited to emphasize negative information. A decade later, the real-life negative impact of the pandemic has also been documented. On its website, the Centers for Disease Control (CDC) in the United States highlights the "major effect on our lives" of COVID-19. The CDC's advice on coping with coronavirusrelated stress is to limit news consumption to "just a couple of times a day" and to disconnect "from phone, tv, and computer screens for a while" (CDC, 2021). The World Health Organization also addresses the stress factor in the "Mental Health Tips" section of its website, encouraging people to "reduce how much you watch, read or listen to news that makes you feel anxious or distressed." (World Health Organization, 2020a).

\section{Aversion and Avoidance}

In discussing news fatigue and avoidance, it is worthwhile to include another term: aversion.

The word's origin is the Latin avertere, which means to 'turn away from'. Indeed, one definition of aversion is: "a feeling of repugnance toward something with a desire to avoid or turn from it" (Merriam-Webster, 2021). One could argue that, for some, news avoidance begins with an aversion to the news. This "feeling of repugnance" may stem from the fatigue generated by the massive amounts of news available to us. The repugnance may also begin with a growing distrust of news organizations and journalists or, perhaps, a lack of confidence in the accuracy of the news stories (Kalogeropoulos, 2017). In all cases, the result can be 
a conscious decision to "turn away" from the news, partially or completely. Partial news avoidance may be fatigue-oriented, with the avoider displaying an aversion only to certain topics or triggers, such as COVID-19, climate change, or Donald Trump's latest announcements. An active, consistent news avoider "will not accept being confronted with any news" (Weitz, 2021). One implication of aversion and avoidance can be a less-informed populace, with citizens who are "are not sufficiently equipped to take decisions in elections or referendums" (Kalogeropoulos, 2017). During a global pandemic, the question could be: are news avoiders sufficiently equipped to make informed decisions about their health? Some believe they are or, at least, they believe they are no less informed than their news-consuming counterparts. In the avoider's view, mainstream, traditional news coverage is largely superficial, providing only a “...distant, watercooler-level awareness of thousands of stories, at least for the few weeks each is popular" (Cain, 2017). Some avoiders proudly proclaim their disdain for modern journalism, stating, (Dobelli, 2019) and declaring it "a ridiculous system" (Dobelli, 2019). These vocal avoiders also encourage others to adopt their perspectives of recognizing that news is "toxic" and to take part in "a news diet" (Dobelli, 2019) as a way of relieving the stress and anxiety caused by media coverage. This speaks to another issue and another reason some cite for avoidance: the overall quality of mainstream journalism and its ability to properly and effectively inform.

\section{Quantity and Quality}

It is difficult to argue that consumers are not informed by news organizations and journalists. Every hour of every day, we can access information from newspaper websites, television and radio stations, and social media platforms. Still, what is the overall relevance of this information for news consumers? How much of it do they actually take the time to read, watch, or listen to because they feel it affects them? As one veteran journalist, now a political communications expert, explained: "Most people who tell me they "don't read the news anymore" are folks who no longer feel the stories presented are relevant to their lives" (BJ, 2021). The issue of relevance, when it comes to news stories, has been the subject of research. One study in 2019 asked consumers to rank a variety of news stories based on what they would read or engage in versus what they would avoid. It found the most relevant stories are those that: "affect their personal lives, as they impinge on members of their family, the place where they work, their leisure activities, and their local community" (Schroder, 2019). To put it simply: "People care most about things that affect them" (Dean, 2014). At times, this relevance can be based on location. A news consumer tends to be "more interested in his local weather forecast than the national outlook. He is more interested in knowing why a police officer is taking a report on his block than somewhere else in the city" (Dean, 2014). However, Dean points out the relevance, the connection, can also be linked to a consumer's emotions or specific interests. "The reader may identify with a range of life experiences, from the emotional shock of losing a job or worrying about a sick child" (Dean, 2014). With this relevance defined, a primary, important question for news organizations and journalists is: how can they ensure 
relevance? A journalist interviewed for this study believes the answer is audience research: "Quite simply the media/journalists need to take some time to understand audience/reader behavior" (ST, 2021). The next step is to act on that research and become more relevant. One American news organization took the time and spent the money to learn what consumers want. The E.W. Scripps company owns 60 television stations across the United States. It sent representatives into 100 homes in various cities to ask about news preferences and relevance. The consumers told them their news needs were not being met and that the non-stop, breakneck speed of the news cycle left them looking for other options: "People craved a deeper look, one that captured their community in full, not just in shards. They wanted longer stories with more context" (Ripley, 2021). Scripps analyzed the research and produced a new television newscast format in some test markets with longer, more in-depth stories "that were seven or eight minutes long - an eternity in the business - audiences watched them to the end, as long as they were well told" (Ripley, 2021). The positive reaction to the deeper storytelling format is mirrored for news organizations that are placing a greater emphasis on an approach called "solutions journalism". The Solutions Journalism Network was founded in 2013 to "change the culture of news" and to foster "rigorous reporting on responses to social problems" (Solutions Journalism Network, 2013). It does this by training journalists to think differently about the stories they cover: "We help reporters, producers, and editors bring the same attention and rigor to stories about responses to problems as they do to the problems themselves" (Solutions Journalism Network, 2013). The goal of the training is to help win back the trust of news consumers who feel disconnected from journalism due to perceived shallow, negative news coverage by providing "a more accurate account of the state of play than does a dystopian ticker tape of corruption and failure" (Solutions Journalism Network, 2013). One study conducted for the organization gave participants different versions of news articles. Some articles focused on a problem, while others focused on the problem and potential solutions. The researchers found that "solutions-based journalism holds promise in at least three areas: heightening audiences' perceived knowledge and sense of efficacy, strengthening the connection between audiences and news organizations, and catalyzing potential engagement on an issue" (Curry and Hammonds, 2014). Of the three areas, strengthening the connection between audiences and news organizations may be the most critical to the future of journalism. In the words of OS, a senior journalist interviewed for this study, the strategy will require a new approach by news organizations and the willingness to change: "to build trust and confidence with news avoiders, we must constantly be challenging how we do things. Current attitudes towards the media don't have to mean the end of journalism - it is merely an opportunity to fast-track essential modernization within the industry to truly reengage with the public we serve" (OS, 2021).

\section{Restoring Trust}

All journalists interviewed for this research are aware of the avoidance trend and the growing numbers of so-called "never-newsers". Some, more than others, 
realize they and their news organizations must do more to regain or keep the public's trust. Greater transparency is a vital component of this. Educating news consumers on how journalists perform their roles and why certain stories and issues are covered over others may be more important than ever before.

"I do think we need to do a better job of educating the public about how we operate, being transparent about the standards and practices and not just the broad strokes but by openly explaining in our journalism why we made specific decisions" (BR, 2021). Recent research conducted on the subject of "trust in news" indicates the public's lack of understanding of journalism is a significant factor: "It suggests that news organisations would benefit from providing clearer cues and signals about who they are, their histories, what they stand for, and how they do their work" (Toff et al., 2021). This theme of transparency and education is shared by another journalist, who believes quality content and coverage will attract and retain consumers: "Be transparent about story selection and process. Let the public know why you're covering a story a certain way. If your content resonates, the audience will show up" (BB, 2021). For some, trust through transparency means less "telling" by journalists and more "showing" by providing the reader with not only the story and the interviews but with the information and facts that have been uncovered by the reporter, such as charts and data. This open sharing of information "respects the reader's intellect" (Stead, 2021) and empowers consumers to "reach their own conclusions" (Stead, 2021) about the story or issue.

\section{Inclusion and Accuracy}

Journalist MA is a recent university graduate. With less than five years of experience, she is relatively new to the profession. Still, she believes she understands why many news consumers have lost trust in journalism in recent years. MA sees it as a reflection of how the industry has evolved into a non-stop, $24 / 7$ entity that endeavors to mirror and compete with the omnipresent social media platforms as news sources. "Fast food journalism, while often well-meaning, has harmed many marginalized communities because it often lacks compassion and sensitivity" (MA, 2021). Understanding the "marginalized communities" is now seen as a priority for growing numbers of news organizations hoping to remain relevant and rebuild sagging audience numbers. In many countries, mainstream news outlets are under increasing pressure to operate with more employees that accurately reflect the diversity of the community, including people in senior and management positions. A 2019 survey of more than 1800 newspapers in the United States found "people of color comprised 21.9 percent of salaried employees," up slightly from 21.8 percent in 2018 (Clark, 2019). The survey also found people of color made up only 18.8 percent of newsroom managers. In the United Kingdom, a 2021 survey indicates a lopsided lack of diversity in newsrooms, with BAME (Black, Asian, and minority ethnic) journalists comprising just 8 percent overall (Spilsbury, 2021). In addition to staffing, newsrooms are also being encouraged, even ordered, to seek out and produce more stories that are relevant to diverse audiences. Younger journalists, especially, see this as a priority: "We need more BIPOC (Black, Indigenous, People of Color) journalists in positions of 
power and covering stories that mean something to people and communities that have been underreported" (RA, 2021). The younger generation of journalists, both white and ethnic, are, at times, frustrated with the slow pace of change to the structure and philosophies of traditional newsrooms: "The institutions that we all trusted for so long have been revealed to not be as objective as they once claimed. In fact, at least in North America, it has been shown time and time again, the objectivity is through a white-centric lens" (BB, 2021). They are adamant a more inclusive, diverse journalism industry can both retain consumers and win back avoiders: "Rethinking our ethics and understandings of bias and objectivity play a big part in building trust" (MA, 2021). Some organizations are taking action. The BBC (British Broadcasting Corporation) first created an internal Diversity and Inclusion Advisory Group in 2014. In 2019, a "refresh" of the group was announced with the chair stating: "I want to support the BBC's ambition to be the most creative broadcaster in the world. To do this, it needs to truly reflect the diversity of all its audiences, both on screen and behind the camera" (Ilube, 2019). The announcement of the "refresh" also revealed that BAME staff in leadership roles at the BBC was at 11.4 percent in 2019, up slightly from 10.4 percent the previous year. In September 2020, the broadcaster unveiled an updated diversity and inclusion plan that calls for new "50:20:12 workforce targets". Specifically, the goals are "50 percent women; at least 20 percent black; Asian or minority ethnic; and at least 12 percent disabled employees" by 2025 (BBC, 2021). In the Canadian province of Manitoba, the CBC (Canadian Broadcasting Corporation) is taking a different approach to inclusion and connecting with its audience. CBC Manitoba launched its first community advisory board in May 2021, advertising for members of the public who meet specific criteria: "The board will be chosen to reflect the ethnocultural, socio-economic, geographic and political diversity of the province". Once selected, the 15 board members will "help add context and perspective" to the newsroom's coverage and provide "advice about specific reporting projects". However, the community members "will not oversee editorial decisions" (MacKenzie, 2021). Conversely, the British online news company Tortoise, founded in 2019, invites people to become members of the newsroom and makes some radical commitments on its website: "We'll show you our inner workings. We'll let you know when we've fallen short" (tortoisemedia.com, 2021). One of its founders, James Harding, is a former head of news at the BBC. In his "What we are for" essay on the Tortoise website, he outlines how the company is different: "We want ours to be a newsroom that gives everyone a seat at the table; one that has the potential to be smarter than any other newsroom, because it harnesses the vast intelligence network that sits outside it" (Harding, 2019). If memberships are an indication, Tortoise's unique approach is effective. Since its launch in 2019, the company claims 100,000 people have joined, paying up to 100 British pounds a year for a seat at the Tortoise table (Tortoise, 2020). 


\section{Conclusion}

The COVID-19 pandemic is unquestionably a global crisis, but it has also provided an opportunity for news organizations and journalists to illustrate their relevance and regain a level of trust with news consumers. In the first months of the pandemic, news audience levels increased significantly as an anxious public sought any and all details of the pandemic, the lockdowns, the death toll, and the safety campaigns. However, as the pandemic continued, audience levels began to dip as consumers found themselves overwhelmed and confused by the amount and variety of COVID-19 information coming from many sources. Of the many questions surrounding news avoidance, one of the most concerning is the effect of fewer people consuming news, at least in traditional formats such as newspapers, television, and radio. The reduction of news audiences is unquestionably a financial concern for news organizations that rely on revenue from advertising to continue operating. Less revenue generally means cuts to resources, as in fewer journalists seeking the facts and telling stories. There is a greater impact: fewer people staying connected and informed of issues and events within their communities and around the world. Journalists interviewed for this study share this avoidance concern. Indeed, GR calls the pandemic "a perfect example" of why professional journalists are needed:

"This was the time for news organizations to present the issues/concerns and to ask questions of medical professionals and government officials on how the virus works, the impact on the healthcare system and the economy, and what plans should have been in place for this public health emergency" (GR, 2021).

Still, there is a very real possibility that news fatigue and avoidance are more than short-term, pandemic-related issues and that growing numbers of consumers are disappointed and disillusioned with news organizations and their products. RG believes this is a crucial time for journalists to illustrate their skills and prove their worth to information-hungry consumers.

"We are swimming in junk. Irrelevant, funny, alarming, distracting, compelling, false junk. Who is going to sift through it? If there's no need for traditional journalism, we would leave this critical path out of the pandemic to individual storytellers and partisans. It would confuse, distort and misinform millions of people" (RG, 2021).

Journalists have long defended themselves and their profession, and, clearly, they continue to do so. However, they must spend less time defending and do more to educate news consumers about the profession and its processes. The lack of knowledge about why reporters and news agencies do what they do invariably leads to misconceptions, stereotypes, and a lack of trust. In its annual Trust Barometer, which measures trust in institutions around the world, the Edelman communications firm found trust in media, both traditional and social, at all-time lows in 2021. A factor in the plummeting trust level appears to be a strong perception of bias among journalists. Of the 33,000 people surveyed by Edelman, $59 \%$ agreed with this statement: "Journalists and reporters are purposely trying to 
mislead people by saying things they know are false or gross exaggerations" (Edelman Communications, 2021). Nearly two-thirds, 61\%, agreed with the statement, "The media is not doing well at being objective and non-partisan" (Edelman, 2021). An essential first step in restoring trust and confidence involves listening more to the concerns of news consumers, in general, and news avoiders, specifically, and acting on those concerns.

"We need to be extra sensitive to the climate. People are very suspicious right now. We have to be better than we have ever been before. That includes making sure we are fair, accurate and we must guard against personal bias creeping into our journalism" (LJ, 2021).

Based on my experience as a journalist, I believe that many news organizations have fallen short in investing the time and money to design and conduct relevant audience research to confirm what consumers want in news coverage, as opposed to assuming to know what they want based solely on experience and what has worked in the past.

"Often it's quite obvious what the audience is really interested in, but some journalists think they know better" (ST, 2021).

Along with research, more transparency in news coverage is an essential element in rebuilding trust and winning back avoiders. Increased levels of transparency can be attained by providing detailed explanations and background on how story elements are gathered, from the interviews to the data and documents cited in the story. For example, publishing or posting entire interviews or transcripts would enable consumers to determine if the interviewee's quotes were taken out of context or influenced by editing. Such transparency would help consumers better appreciate the role of the journalist by helping them understand the news process and the work involved in finding and telling stories, from the initial concept to the final published version.

"We also need to "pull back the curtain" more often. Show people where a story came from, why and how we covered it" (MR, 2021).

This transparent approach would serve to clarify and alleviate long-standing public misconceptions of bias among reporters and news organizations. It would also help engage disenchanted news consumers and entice them to watch, read, and listen once again.

"Consumers are on high alert for balance and objectivity. If they see you are making a consistent effort to be fair, they will consume your product" (LJ, 2021).

Greater transparency and improved understanding could also help attract a new and younger audience, something sorely needed for traditional media organizations, especially, as their existing audiences age and die off. In 2017, a survey of American adults found the median age of cable news consumers was 60 
for CNN and 65 for FOX News (Katz, 2018). A 2020 survey by Statista indicated that only 15 percent of American adults aged 18-29 watch cable news daily or regularly. Perhaps not surprisingly, 42 percent of the 18-29 demographic admitted they never watch cable news (Statista, 2020). The public's overall interest in news has declined in many countries, according to research conducted by the Reuters Institute for the Study of Journalism. Its 2021 Report on News shows the number of people who say they are "very or extremely interested" in the news has dropped by an average of five percentage points since 2016. While there has been little or no change in some countries (Germany, Netherlands), the drop is dramatic in others, including a "17 percentage point drop in Spain and the UK, 12 points in Italy and Australia, and eight in France, and Japan." (Newman, 2021). Journalists and news leaders must ensure the coverage and story selection are relevant and reflective of today's society and issues. Improved trust and increased relevance can also be attained when news organizations address the lack of diversity and alternative perspectives in newsrooms and strive for improved understanding of ethnic and marginalized communities. The world has changed dramatically in the past 20 years but, apart from technology, little has changed in how newsrooms and journalists inform the public. New perspectives are required from a new generation of informed, diverse journalists who are willing to listen to and learn from news consumers and news avoiders. It seems clear the "old ways" are simply no longer viable and, frankly, no longer accepted by a more discerning, demanding public.

"We need to challenge our own unconscious bias and that of our colleagues to ensure journalism truly reflects the priorities of our entire audience" (OS, 2021).

Still, just as there are news avoiders among consumers, there are those within journalism who refuse to alter their traditional, tested methods of storytelling. This reluctance, or resistance, is at their peril. Without a revised focus and attitude, journalism will continue to falter, and, in many cases, news organizations will continue to fail in the eyes of consumers, and in the eyes of some journalists. MA is the youngest journalist interviewed for this research. She only recently graduated from journalism school and has the least practical experience by far. Still, she is the future of a struggling, embattled profession and understands it must adapt to the changing perspectives and demands of society.

"Resisting change and failing to innovate only results in layoffs. If submitting to an ever-changing media landscape keeps journalism afloat but makes "traditional" reporting irrelevant, so be it" (MA, 2021).

It is clear both the consumers of news and those who produce it are frustrated with the current environment, but it is the journalists and news organizations that have the most to lose if nothing changes. The pandemic is an opportunity for journalists to display their relevance. The question is: can they regain the trust of the public and win back the news avoiders? 


\section{References}

Aslam, F. (2020, July 8). Sentiments and emotions evoked by news headlines of coronavirus disease (COVID-19) outbreak. Humanities and Social Sciences Communications, $7(1), 23$.

BBC (2021). Strategy and reports. Workforce diversity \& inclusion. BBC.

Bricker, D. (2021). Trust in news. Ipsos Public Affairs.

Cain, D. (2017, September 6). Five things you notice when you quit the news. Raptitude. Com.

Centers for Disease Control (2021). Coping with stress. Centers for Disease Control.

Clark, M. (2019). Digital-only platforms drive race and gender inclusion among newsrooms in 2019 ASNE newsroom diversity survey. News Leaders Association.

Corbin, J., Strauss, A., Strauss, A. L. (2015). Basics of Qualitative Research. SAGE Publications.

Curry, A., Hammonds, K. (2014, June). The power of solutions journalism. The University of Texas at Austin, Center for Media Engagement.

Dean, W. (2014). Good stories prove their relevance to the audience. American Press Institute.

Dobelli, R. (2019). News lunch. Retrieved from: https://www.dobelli.com/en/essays/newlunch/. [Accessed 18 February 2020.]

Edelman Communications. (2021). 2021 Edelman Trust Barometer. Edelman Communications.

Gottfried, J. (2020). Americans' news fatigue isn't going away-About two-thirds still feel worn out. Pew Research Center.

Harding, J. (2019, January 14). What we are for. Tortoise.

Ilube, T. (2019). New BBC diversity and inclusion advisory group to meet today. Media Centre.

Johnson, T. (2020, December 24). Cable news networks see big gains in viewership during tumultuous 2020. Deadline.

Johnston, W. M., Davey, G. C. L. (1997). The psychological impact of negative TV news bulletins: the catastrophizing of personal worries. British Journal of Psychology, 88(1), 85-91.

Kalogeropoulos, A. (2017). Reuters Institute digital news report 2017. Reuters Institute.

Katz, A. J. (2018, January 19). Here's the median age of the typical cable news viewer. TVNewser.

Kight, S. W. (2017, September 22). The insane news cycle of Trump's presidency in 1 chart. Axios.

Kleis Nielsen, R., Fletcher, R., Kalogeropoulos, A., Simon, F. (2020, October 27). Communications in the coronavirus crisis: lessons for the second wave. Reuters Institute for the Study of Journalism.

MacKenzie, L. (2021, May 29). Want to play a role in CBC Manitoba's journalism? Join our 1st ever community advisory board. CBC News.

McCombs, M., Poindexter, P. (1983). The duty to keep informed: news exposure and civic obligation. Journal of Communication, 33(2), 88-96.

Merriam Webster (2021). Definition of aversion. Merriam Webster.

Mitchell, A., Oliphant, B. J., Shearer, E. (2020, April 29). About seven-in-ten U.S. adults say they need to take breaks from COVID-19 news. Pew Research Center's Journalism Project.

Newman, N. (2018). Digital news report 2018. Reuters Institute for the Study of Journalism.

Newman, N. (2020, May 20). Overview and key findings of the 2019 digital news report. Reuters Institute Digital News Report. 
Newman, N. (2021). Overview and key findings of the 2021 digital news report. Reuters Institute for the Study of Journalism.

Ripley, A. (2021, May 18). Can the news be fixed? The Atlantic.

Sacerdote, B., Sehgal, R., Cook, M. (2020, November 23). Why is all COVID-19 news bad news? NBER.

Schroder, K. C. (2019, February). What do news readers really want to read about? Reuters Institute for the Study of Journalism.

Solutions Journalism Network (2013). Who we are. Solutions Journalism Network.

Spilsbury, M. (2021, May). Diversity in journalism. National Council for the Training of Journalists.

Statista. (2020). Frequency of cable news consumption in the U.S. 2020, by age group. Statista.

Stead, S. (2021, May 29). Show, don't tell with more data. The Globe and Mail.

Stosny, S. (2017, February 6). He once called it "Election stress disorder". Now, the therapist says we're suffering from this. Washington Post.

The Economist (2020, December 16). Only the world wars have rivalled COVID-19 for news coverage. The Economist.

Toff, B., Badrinathan, S., Mont'Alverne, C., Ross Arguedas, A., Fletcher, R., Kleis Nielsen, R. (2021). Listening to what trust in news means to users: qualitative evidence from four countries. Reuters Institute for the Study of Journalism.

Tortoise (2020) Welcome to Tortoise. Tortoise.

Wakefield, B. J. (2016, June 15). Social media "outstrips TV" as news source for young people. BBC News.

Weitz, S. (2021, January 8). It's not just news fatigue: News avoidance presents a whole new problem. Shout Out UK.

World Health Organization (2020a) \#HealthyAtHome - Mental health. World Health Organization.

World Health Organization (2020b) Let's flatten the infodemic curve. World Health Organization. 